\title{
CRISPR/Cas9-mediated genome editing in rice cv. IPB3S results in a semi-dwarf phenotypic mutant
}

\author{
NURHAYATI ${ }^{1,2}$, SINTHO WAHYUNING ARDIE $^{2}$, TRI JOKO SANTOSO ${ }^{3, \bullet}$, SUDARSONO $^{2, \bullet \bullet}$ \\ ${ }^{1}$ Program of Plant Breeding and Biotechnology, Graduate School, Institut Pertanian Bogor. Jl. Raya Dramaga, IPB Dramaga Campus, Bogor, West Java \\ 16680 , Indonesia. \\ 2Plant Molecular Biology Laboratory, Department of Agronomy and Horticulture, Faculty of Agriculture, Institut Pertanian Bogor. Jl. Meranti, IPB \\ Dramaga Campus, Bogor 16680, West Java, Indonesia. Tel.: +62-251 8629354, 8629353, v•email: sudarsono_agh@apps.ipb.ac.id \\ ${ }^{3}$ Research and Development Center for Biotechnology and Genetic Resources. Jl. Tentara Pelajar No. 3A, Cimanggu, Bogor 16111, West Java, \\ Indonesia. Tel.: +62-251- 833882, Fax.: +62-251-833882. •email: trijsant@yahoo.com; trijoko@ pertanian.go.id
}

Manuscript received: 2 August 2021. Revision accepted: 21 August 2021

\begin{abstract}
Nurhayati, Ardie SW, Santoso TJ, Sudarsono. 2021. CRISPR/Cas9-mediated genome editing in rice cv. IPB3S results in a semi-dwarf phenotypic mutant. Biodiversitas 22: 3792-3800. IPB3S is Indonesian lowland rice and high-yielding cultivar. However, plant height posture makes it prone to lodging which could reduce the yield. This study aimed to edit the $G A_{20} O x 2$ gene by introducing CRISPR/Cas9 $\mathrm{GA}_{20} O x 2$ construct into IPB3S and developing the semidwarf rice mutants. Immature embryo explants of IPB3S were used for the transformation process mediated by EHA105 strain of Agrobacterium tumefaciens carrying pC1300-Cas $9 / G A_{20} O x 2$ and by changing the regeneration medium composition. PCR analysis showed that rice cv. IPB3S genetic transformation gained putative mutant T0 lines carrying the hpt gene (growth efficiency was $47.9 \%$, while transformation efficiency was $19.3 \%$ ). Using the developed regeneration medium, we have obtained 24 putative rice cv. IPB3S T0 mutant lines carrying hpt. The best medium for regenerating IPB3S was the A medium (regeneration efficiency 73.3\%). IPB 8 and IPB 14 were potential to evaluate in the next generation. The shortest plant height for the T1 generation was observed in the IPB 8-3 mutant.
\end{abstract}

Keywords: Agrobacterium tumefaciens, CRISPR/Cas9, GA20Ox2, rice

\section{INTRODUCTION}

Rice is a staple crop globally and feeds more than $50 \%$ of the world's population, which is widely cultivated, especially in Asia, Latin America, and Africa (Khush 2005; Wang and Li 2011). Most developing countries, including Indonesia, need rice as the primary food source. In recent decades, the human population has grown rapidly, and the rice demands also increased. Therefore, the improved yield has become one of the rice breeder's objectives (Wang et al. 2008; Xing and Zhang 2010; Zeng et al. 2020). Improving plant height architecture is essential and directly associated with environmental adaptation and yield improvement. Lodging resistance and yield improvement have become functional problem solving since the green revolution era. IPB3S is a new type of lowland rice, and the rice varieties produced tend to be resistant to tungro, blast, and leaf blight diseases, thereby reducing inputs and production costs with high yields. It has a plant height of about $\pm 112-118 \mathrm{~cm}$, has $218-223$ grain per panicle, 1000 grain weight of about 28.2 grams, an average yield of 7.0 tons $\mathrm{ha}^{-1}$, and yield potential of about 11.2 tons ha- $\mathrm{ha}^{-1}$. However, it was prone to lodging because of its height posture.

IR8 is a semidwarf rice variety known as the green revolution rice, which has succeeded in increasing rice production and preventing food shortages in Asia from the 1960 s to the 1990s (Ashikari et al. 2002; Sasaki et al. 2002). Cloning and sequencing analysis revealed that the semidwarf phenotype of IR8 comes from the $s d l$ gene. Mutation in the $s d 1$ gene which encoding an oxidase enzyme $\left(\mathrm{GA}_{20}\right.$ oxidase/ $\left.\mathrm{GA}_{20} \mathrm{Ox}\right)$ involved in the biosynthesis of gibberellin. Four loci of $G A_{20} O x$ were identified in the rice genome $\left(G A_{20} O x-1,-2,-3,-4\right)$. Mapping analysis revealed that $G A_{20} O x-2$ is positioned on the long arm of chromosome 1, which is identical to the rice green revolution gene (Sasaki et al. 2002; Spielmeyer et al. 2002).

Gibberellin (GA) regulates many aspects of plant growth and development (Chen et al. 2016; Chhun et al. 2007; Davière and Achard 2013). The role of GA in determining plant structure had significant impacts on agriculture since it was associated with the development of semidwarf rice varieties that altered GA responses to a vast increase in grain yields during the green revolution (Ashikari et al. 2002; Itoh et al. 2002; Liu et al. 2018). The function of GA in plants includes seed germinations, stem elongation, leaf expansion, trichome development, pollen maturation, and flowering induction (Davies 2004; Han et al. 2019). Hence, the GA deficient mutant plants exhibit a dwarf phenotype. The GAs consists of large diterpenoid carboxylic acid groups such as $\mathrm{GA}_{1}$ and $\mathrm{GA}_{4}$. The GAs biosynthesis is under the control of molecular mechanisms associated with phytohormones (Thomas and Hedden 2018).

The higher the rice plant height, the more sensitive to lodging and yield reduction. Lodging and yield reduction are common problems in rice breeding. Therefore, it is 
necessary to develop high-yielding and lodging tolerance rice varieties. Lodging tolerance can be resolved through CRISPR/Cas9 genome editing system. Clustered regularly interspaced short palindromic repeats (CRISPR) technology was highly promising to edit targets sequence and proven to be passed on to the next generation. It has evolved from bacterial defense studies against bacteriophage (Cong et al. 2013; Jiang et al. 2013; Jinek et al. 2012; Wiedenheft et al. 2012). CRISPR-associated protein (Cas) system type II is derived from Streptococcus pyrogens, the most popular method and widely used for gene editing (Cong et al. 2013; Jinek et al. 2012). Recently, there were several reports of successful CRISPR/Cas9 system in plants mediated Agrobacterium tumefaciens and tissue culture. Many studies have been successfully carried out, such as in Arabidopsis thaliana and Nicotiana benthamiana (Bortesi and Fischer 2015), wheat (Wang et al. 2014), maize (Liang et al. 2014), tomatoes (Ron et al. 2014), and rice (Zhang et al. 2014; Shan et al. 2013). This study aimed to edit the $G A_{20} O x 2$ gene by introducing the CRISPR/Cas9 $\mathrm{GA}_{20} O \times 2$ construct into IPB3S immature embryos and developing semidwarf IPB3S phenotype.

\section{MATERIALS AND METHODS}

\section{Plant materials and measurements of plant transformation}

IPB3S seeds were sown on the soil in a growth chamber for 21 days after germination. Seedlings were transferred to the pot and raised until anthesis around 70-80 days after being transferred. The immature embryo was used as explants for the genetic transformation (8-12 days after anthesis).

\section{Vector construction}

Design and construction were previously described by Santoso et al. 2015. CRISPR/Cas9 $\mathrm{GA}_{20} O \times 2$ cassette was transformed into the binary vector pC1300-Cas9. The binary vector loading of two sgRNAs was used for genetic transformation mediated by Agrobacterium tumefaciens strain EHA105, containing the Kanamycin and hygromycin phosphotransferase (HPT) resistance genes in the plasmid backbone. HPT was driven by the cauliflower mosaic virus 35s (CaMV 35s) promoter and cauliflower mosaic virus polyA (CaMV PolyA) terminator. The Cas9 was driven by the ubiquitin promoter ( $\mathrm{pUBI}$ ), and the nopaline synthase terminator (tNOS) was used to edit the target sites (Figure 1). The CRISPR/Cas9 cassette was designed to target $G A_{20} O x 2$ specifically in the first exon with high efficiency to achieve the expected mutation.

\section{Plant transformation}

Agrobacterium tumefaciens strain EHA105 carrying CRISPR/Cas9 $\mathrm{GA}_{20} O \times 2$ cassette was grown overnight at $28^{\circ} \mathrm{C}$ incubator on LB (Luria-Bertani) medium supplemented with $50 \mathrm{mg} \mathrm{L}^{-1}$ kanamycin as an antibiotic. A single colony was cultured into YEP (Yeast Extract Peptone) medium supplemented with appropriate antibiotics and grown with shaking overnight at room temperature. Cells were harvested two next days, then cultured into $\mathrm{AB}$ medium supplemented with appropriate antibiotics and grown two days overnight at $28^{\circ} \mathrm{C}$ incubator. The colonies were used before transformation and diluted in co-cultivation medium by final $\mathrm{OD}_{600}$ of 0.3 and added with $100 \mu \mathrm{M}$ acetosyringone. The immature embryo of rice cv. IPB3S lines was used as explants for the genetic transformation. The immature embryo was inoculated by $10 \mu \mathrm{L}$ of diluted Agrobacterium tumefaciens. Plants were incubated at $25^{\circ} \mathrm{C}$ under continuous exposure to light. The method for Agrobacterium-mediated transformation, the calculation of transformation efficiency, and regeneration efficiency was according to Hiei and Komari (2008), while the transformation medium was according to Slamet-Loedin et al. (2014) with some modified regeneration medium composition (Table 1). Transformation and regeneration efficiency were calculated as follow:

Transformation efficiency $(\%)=$
$\frac{\text { Number of hygromycin resistant calli }}{\text { Number of responding embryo }} \times 100 \%$

Regeneration efficiency $(\%)=$ Number of hygromycin resistant planlets Number of hygromycin resistant calli $\times 100 \%$

\section{Selectable marker detection}

The regenerated putative $\mathrm{T} 0$ and $\mathrm{T} 1$ mutant rice lines were acclimatized and molecularly evaluated by PCR for the presence of selectable marker hygromycin ( $h p t)$. Genomic DNA was isolated from an individual leaf of each plant by the CTAB (Cetyl trimethyl ammonium bromide) method, according to Doyle and Doyle 1990, by some modification. DNA was amplified using Hyg primer pair with an amplicon size of 550 bp (Table 2) and plant Kit (Kapa Biosystems). The DNA fragment was confirmed on gel electrophoresis agarose type $1 \mathrm{~A} 1 \%$ and visualized by EtBr.
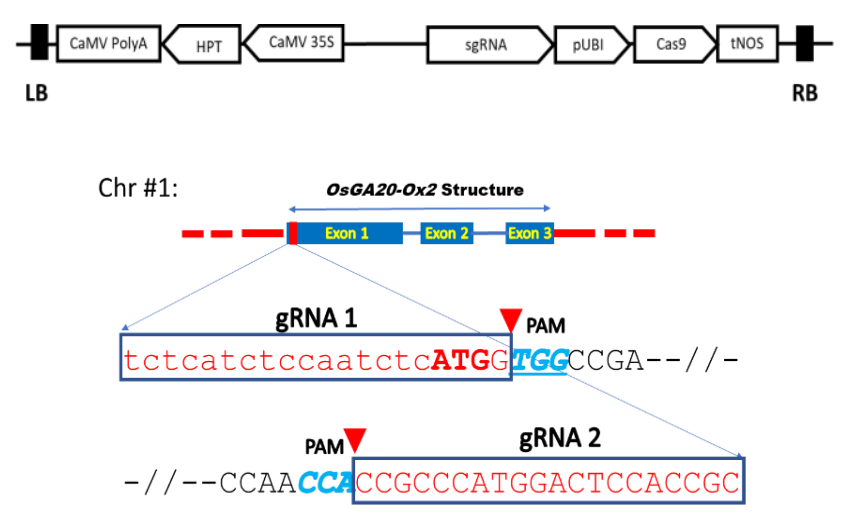

(Guide RNA (gRNA) 1,2 sequences, $\nabla$ : Cutting sites TGG/CCA: PAM sequences, ATG: start codon)

Figure 1. Schematic diagram of CRISPR Cas9/sgRNA $G A_{20} O x 2$ target sites in $\mathrm{pC} 1300 \mathrm{GA} \mathrm{A}_{20} \mathrm{O} \times 2$ binary vector 
Table 1. Regeneration medium compositions supplemented with different growth regulators for regenerating IPB rice plantlets

\begin{tabular}{ll}
\hline Medium & Composition \\
\hline A & MS + Kinetin 2 $\mathrm{mg} \mathrm{L}^{-1}+$ NAA $5 \mathrm{mg} \mathrm{L}^{-1}+$ Putrescine $1 \mathrm{mM}+$ Hygromycin $20 \mathrm{mg} \mathrm{L}^{-1}$ \\
B & MS + BAP 2 mg L+1 IAA $0.8 \mathrm{mg} \mathrm{L}^{-1}+$ Zeatin $0.1 \mathrm{mg} \mathrm{L}^{-1} \mathrm{~L}+$ Putrescine $1 \mathrm{mM}+$ Hygromycin $20 \mathrm{mg} \mathrm{L}^{-1}$ \\
C & MS + BAP 2 $\mathrm{mg} \mathrm{L}^{-1}+$ NAA $0.5 \mathrm{mg} \mathrm{L}^{-1}+$ Kinetin $0.5 \mathrm{mg} \mathrm{L}^{-1}+$ Putrescine $1 \mathrm{mM}+$ Hygromycin $20 \mathrm{mg} \mathrm{L}^{-1}$ \\
D & MS + Kin $2 \mathrm{mg} \mathrm{L}^{-1}+$ NAA $1 \mathrm{mg} \mathrm{L}^{-1}+$ Putrescine $1 \mathrm{mM}+$ Hygromycin $20 \mathrm{mg} \mathrm{L}^{-1}$ \\
\hline
\end{tabular}

Table 2. Nucleotide sequences of primers used to hpt gene detection

\begin{tabular}{|c|c|c|c|}
\hline Primer & Sequence $(5 '$ - 3') & Product length & Aimed \\
\hline Hyg-F & ACTATCGGCGAGTACTTCTA & $550 \mathrm{bp}$ & Hygromycin gene detection \\
\hline Hyg-R & CATGTCTATCACTGGCAAAC & & \\
\hline GA20-F & ATGTCTGTCCAGTGGCAACC & $1300 \mathrm{bp}$ & $G A_{20} O x 2$ gene sequencing analysis \\
\hline GA20-R & GGTCGGTGTGTTTTGAATTT & & \\
\hline
\end{tabular}

\section{Plant materials and agronomic trait measurements}

Wildtype, escape transformant (negative presence of $h p t$ ), and T1 transgenic line was germinated in the screen house. Each pot contained two plants with a planting distance above 15 centimeters under natural conditions. The Agronomic traits were analyzed after rice was harvested. A total of 50 individual plants were used to measure plant height, culm height, total tiller numbers, internode numbers, panicle length, total grain, filled grain and empty grain per panicle, and 100-grain weight. Data analysis was performed by using $\mathrm{R}$ studio software.

\section{DNA sequence analysis of sgRNA target region of individual T1 plants}

DNA sequence analysis was used for mutation detection on the target site. Total DNA was isolated from an individual leaf of each T1 progeny GA20 primers were used to amplify a fragment of the $G A_{20} O x 2$ gene, targeting the exon- 1 and both of sgRNAs as the target mutation (Table 2). Sequence analysis was done using Geneious software 10.0.3.

\section{RESULTS AND DISCUSSION}

\section{Transformation efficiency}

The swelling of the scutellum area in the embryo occurred seven days after the embryo was cultured on an N6 medium and was followed by the appearance of coleoptiles. Calli development was within four weeks on the selection medium with the addition of hygromycin 30 $\mathrm{mg} \mathrm{\textrm {L } ^ { - 1 }}$. Furthermore, the calli were transferred to the regeneration medium supplemented with hygromycin 20 $\mathrm{mg} \mathrm{L}^{-1}$. In the regeneration medium, subculture was carried out up to two times, every two weeks until shoots were regenerated. Subsequently, the calli that have regenerated shoots were cultured into a rooting medium to generate plantlets. Plantlets were ready to acclimatize within two weeks on the rooting medium (Figure 2). Transformation of the CRISPR/Cas9 $\mathrm{GA}_{20} O x 2$ construct showed that not all zygotic embryos explants grew on cultivation medium. The percentages of callus growth on the selection medium after genetic transformation were relatively low. Selection medium supplemented with hygromycin $\left(20 \mathrm{mg} \mathrm{L}^{-1}\right)$ effectively inhibited non-transformed cells. The percentages of callus growth on selection medium supplemented with hygromycin in the IPB3S genotype was $47.9 \%$, while transformation efficiency was $19.3 \%$ (Table 3).

Transformation of indica rice has the difficulties such as the low ability of embryos to form an embryogenic callus, low regeneration of callus, and browning of tissue after co-cultivation (Lin and Zhang 2005; Ramesh et al. 2009). The addition of acetosyringone into the cocultivation medium induced vir genes that play a role in transferring genes contained in the T-DNA region from Agrobacterium to the plant genome target. Scutellum carrying hpt gene develop primary embryonic callus characterized by a yellowish-white globular callus $0.5-1 \mathrm{~cm}$ in diameter (Hiei and Komari 2008). The regeneration efficiency of transformants is an obstacle in plant genetic transformation. The potential for callus induction and regeneration of rice tissue culture depends on several factors such as the genotype of the plant used, the type and physiological status of explants, the composition and concentration of salt, organic components, and growthregulating hormones in the medium (Ge et al. 2006; Lin and Zhang 2005). Ge et al. (2006) succeeded in obtaining high transformation and regeneration efficiency of some indica cultivars such as Minghui 63, Zhenshan 97, IRBB13, IRBB10, IRBB4, and IR24 by some modification of callus induction and regeneration medium.

Table 3. Transformation efficiency of rice cv. IPB3S mediated by Agrobacterium tumefaciens

\begin{tabular}{cccccc}
\hline Genotype & $\begin{array}{c}\text { Inoculated immature } \\
\text { embryos [A] }\end{array}$ & $\begin{array}{c}\text { Responding embryos } \\
{[\mathbf{B}]}\end{array}$ & $\begin{array}{c}\text { Hygromycin } \\
\text { resistant calli [C] }\end{array}$ & $\begin{array}{c}\text { Growth efficiency } \\
(\%)[B / A]\end{array}$ & $\begin{array}{c}\text { Transformation } \\
\text { efficiency (\%) [C/B] }\end{array}$ \\
\hline IPB3S & 648 & 311 & 60 & 47.9 & 19.3 \\
\hline
\end{tabular}



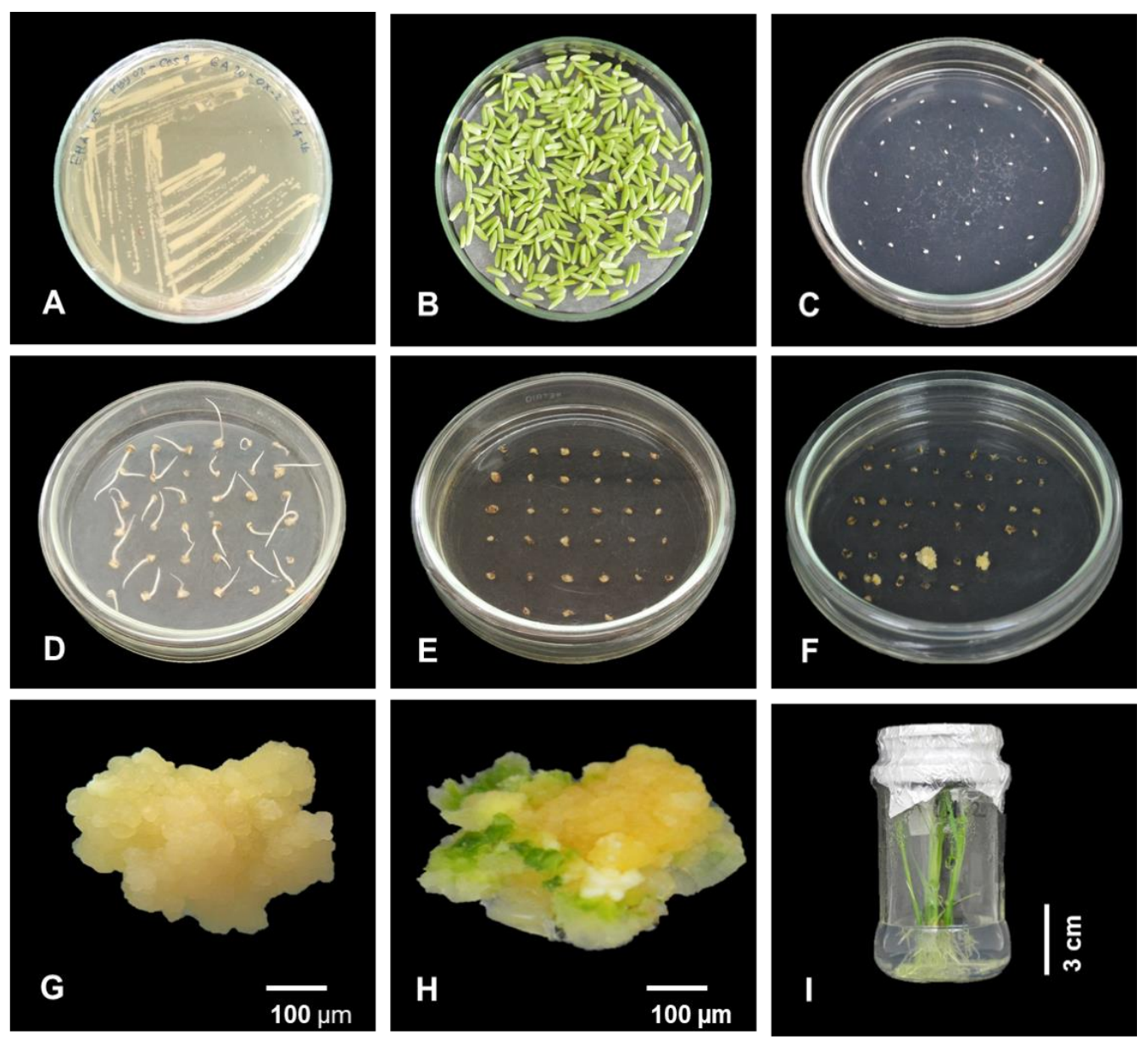

Figure 2. Transformation and regeneration stages of IPB3S mediated Agrobacterium tumefaciens: (A) Isolate of A. tumefaciens for 3 days on $\mathrm{AB}$ medium, (B) Immature seeds of IPB3S for 8-12 days after anthesis used as explant, (C) Immature embryos of IPB3S and $A$. tumefaciens suspension on cultivation medium (A201), (D) Immature embryos of IPB3S for 7 days on A201 medium showed coleoptiles elongation, (E) Immature embryos of IPB3S for 5 days on resting medium (A202), (F) transformant callus for 10-30 days on selection medium (A203), (G) First sub-cultured of embryonic callus for 10 days on regeneration medium (A204), (H) Second subcultured of embryonic callus for 10 days on A204 showed green spot, (I) T0 plantlets for 10 days on rooting medium (A205)

Regeneration of plants in genetic transformation is one of the crucial stages to obtain transformant individuals. The regeneration ability of each genotype is different. Some of the alternatives that can be done to increase the success of plant regeneration include modifying growth regulators and eliminating antibiotics in the regeneration medium. In this study, four modifications of different growth regulators were carried out on the regeneration medium used. Successful calli development began with fairly good cell proliferation during the first subculture on regeneration medium and developed into embryonic cells. An embryonic cell is characterized by globular, crumbly, and yellowish forms. They grew well on a regeneration medium without antibiotics to induce shoots and roots formation (Figure 2). Modification of the regeneration medium has succeeded in obtaining 151 T0 lines of IPB3S hygromycin-resistant plantlets. Plantlets that were successfully grown on a regeneration medium with hygromycin were pre-acclimatized in tubes filled with water. At this stage, initial screening was carried out using PCR for the hygromycin resistance gene. Confirmation of the hygromycin gene showed that there were still hygromycin-negative plants that could grow on medium containing hygromycin. The results of the PCR test showed that 24 plants were positive for carrying the hygromycin gene. The best medium for regenerating IPB3S is the $\mathrm{C}$ medium (regeneration efficiency 73.3\%) (Table 4).

\section{Regeneration efficiency}

The addition of antibiotics can also reduce the ability of plant regeneration. Modification of medium was needed at the regeneration stage with different types and concentrations of growth regulators. Cefotaxime and Vancomycin antibiotics were also eliminated. According to (Ogawa and Mii 2007), the antibiotics cefotaxime and vancomycin function to eliminate Agrobacterium were left in the transformation process. Cefotaxime has an inhibitory effect on the shoot, and root induction also could cause loss of phytohormone balance. Thus, it affects regeneration efficiency. The regeneration ability in rice was influenced by genotype, type of explants, primary medium, the combination of growth regulators, periods, and culture conditions (Sahoo and Tuteja 2012; Vennapusa et al. 2015). The combination of growth regulators used includes 
auxins and cytokines. Auxin has a role in cell growth, apical dominance of callus formation, and organogenesis. Auxin concentrations such as 2,4-D, commonly used for organogenesis, are 2-2.5 mg L-1 (Hiei and Komari 2008). Other growth regulators such as kinetin and benzyl adenine (BA or BAP) were the most widely used in the tissue culture medium. It could induce cell division, shoot proliferation, and shoot morphogenesis (Hiei and Komari 2006).

\section{Detection hygromycin (hpt) genes using PCR}

This study aimed to select plants at an early stage of plant development and reduce the growth of unexpected cells. Hygromycin was used as selectable markers in this study. Hygromycin phosphotransferase is an antibiotic that inhibits protein synthesis so that it is effectively used as a selectable marker. The plantlets that survived in the rooting medium by adding $20 \mathrm{mg} \mathrm{L}^{-1}$ hygromycin were detected by PCR analysis using Hyg primers. Molecular confirmation is needed of the hpt gene in the T-DNA plasmid region inserted in the plant genome of the first generation (T0) and second-generation (T1). Plants that positively contain the hpt gene indicated that CRISPR/Cas9 $G_{20} O x 2$ cassettes were successfully integrated into the plant genome. Electrophoregram on agarose gel $1 \%$ shown that hpt gene detection has succeeded in obtaining $24 \mathrm{~T} 0$ generation of rice cv. IPB3S and the amplicon size $550 \mathrm{bp}$ (Figure 3 ).

PCR analysis was performed using specific primers for the $h p t$ marker gene. The position of the hpt gene in the TDNA region in the pC1300 $G A_{20} O x 2$ plasmid is on the left border (Left Border). The presence of the hpt marker gene indicates the presence of another gene in the same T-DNA. In this study, a sequence of Cas9 and gRNA. Thus if PCR results show hpt gene bands in the plant genome, it indicates that the Cas9 and gRNA target sequences have also been integrated into the plant genome (Figure 1). The presence of hpt genes in the genome to indicate the integration of the target gene has also been done. According to (Miki and McHugh 2004), gene marker selection was needed in genetic transformation.

\section{Agronomic traits of T0 lines in the greenhouse}

T0 plants in the greenhouse showed a good response, and each individual was fertile and able to produce T1 seeds. There were 24 concrete plants of $h p t$ genes; 2 plants showed lower plant height than wildtype and negative transformants. They were showed potential characters to be evaluated by the T1 generation. They were IPB- 8 and IPB14. Individual $\mathrm{T} 0$ plants were selected based on plant height, tiller number, panicle length, and total grain numbers per panicle. The IPB-8 has the lowest height compared to wild-type and non-transformed regenerants. The plant height of the IPB-8 height was $98.2 \mathrm{~cm}$, while the wildtype was $118.0 \mathrm{~cm}$ and the non-transformed regenerants was $128.9 \mathrm{~cm}$. IPB-14 has the highest tiller number compared to wildtype and non-transformed regenerants. The IPB-14 has nine tillers, while the wildtype was eight tillers and the non-transformed regenerants were three. As for the panicle length, they were similar among the wildtypes, the non-transformed regenerants, the IPB-8, and the IPB-14. Table 5 showed that IPB- 8 has both the lowest panicle length and total grain numbers per panicle, respectively. The distribution of the observed character in the T0 population is shown in Figure 4.

\section{Agronomic traits of T1 lines in the greenhouse}

The agronomic traits of wildtype, negative transformant, and mutant T1 lines were recorded. Two number of the selected T0 lines that showed lower plant height were evaluated in T1 lines. There were 50 plants in the population. The observed character involved plant height, stem length, number of tillers, number of internodes, panicle length, number total grain/panicle, and weight of 100-grain. The editing of the $G A_{20} O x 2$ gene in $\mathrm{T} 1$ lines showed a change in the observed characters when compared to wild type and negative transformants. There were five individuals of T1 lines that showed shorter plant height compared to wild type and negative transformants. The mean performances for morphological traits showed that differences among all agronomic traits except panicle length. They were IPB-8-3, IPB-8-4, IPB-8-6, IPB-14-10, and IPB-14-12. The height of the selected T1 plants ranged from 99.5-117.0 cm compared to 141.6 and $131.8 \mathrm{~cm}$ of wild type and negative transformants, respectively. Followed by stem length ranged 87.0-104.6 cm compared to 121.4 and $114.3 \mathrm{~cm}$. The number of tillers ranged 2-4 tillers compared to 5.2 and 7.2 tillers, internodes number 4.0-5.0 compared to 5.0, panicle length of 20.5-40.3 cm compared to 27.9 and $31.0 \mathrm{~cm}$, the number of total grains ranged 54.0-165.3 grains compared to 152.9 and 212.8 grains, the weight of 100-grains 2.5-3.2 grams compared to 2.9 and 2.8 grams (Table 6).

Table 4. Regeneration and selection efficiency of putative mutant $\mathrm{T} 0$ lines in various rice regeneration medium

\begin{tabular}{|c|c|c|c|c|c|c|}
\hline Genotype & Medium & $\begin{array}{c}\text { Hygromycin } \\
\text { resistant calli [D] }\end{array}$ & $\begin{array}{c}\text { Hygromycin resistant } \\
\text { plantlets [E] }\end{array}$ & $\begin{array}{c}\text { Hygromycin positive } \\
\text { plantlets [F] }\end{array}$ & $\begin{array}{c}\text { Regeneration } \\
\text { efficiency \% [E/D] }\end{array}$ & $\begin{array}{c}\text { Selection efficiency } \\
\%[\mathrm{~F} / \mathrm{E}]\end{array}$ \\
\hline \multirow{4}{*}{$\overline{\mathrm{IPB} 3 \mathrm{~S}}$} & $\mathrm{~A}$ & 30 & 22 & 14 & 73.3 & 63.6 \\
\hline & B & 30 & 1 & 1 & 3.3 & 100.0 \\
\hline & $\mathrm{C}$ & 30 & 5 & 4 & 16.7 & 80.0 \\
\hline & $\mathrm{D}$ & 30 & 9 & 5 & 30.0 & 55.6 \\
\hline Total & - & 120 & 37 & 24 & - & - \\
\hline Average & - & - & - & - & - & 74.8 \\
\hline
\end{tabular}


Tabel 5. Agronomic traits of $\mathrm{T} 0$ lines

\begin{tabular}{lcccccc}
\hline \multicolumn{1}{c}{ Genotype } & $\begin{array}{c}\text { Plant height } \\
(\mathbf{c m})\end{array}$ & Tiller numbers & $\begin{array}{c}\text { Panicle length } \\
(\mathbf{c m})\end{array}$ & $\begin{array}{c}\text { Total } \\
\text { grain/panicle }\end{array}$ & $\begin{array}{c}\text { Filled } \\
\text { grain/panicle }\end{array}$ & $\begin{array}{c}\text { Empty } \\
\text { grain/panicle }\end{array}$ \\
\hline IPB WT & 118.0 & 8 & 31.5 & 223.3 & 123.1 & 100.2 \\
IPB T- & 128.9 & 3 & 26.3 & 146.7 & 31.7 & 115.0 \\
IPB-8 & 98.2 & 7 & 25.0 & 100.0 & 30.0 & 70.0 \\
IPB-14 & 114.8 & 9 & 25.2 & 145.4 & 5.8 & 139.6 \\
\hline
\end{tabular}

Tabel 6. Agronomic traits of $\mathrm{T} 1$ lines

\begin{tabular}{lccccccc}
\hline Genotype & $\begin{array}{c}\text { Plant height } \\
(\mathbf{c m})\end{array}$ & $\begin{array}{c}\text { Stem length } \\
(\mathbf{c m})\end{array}$ & $\begin{array}{c}\text { Tillers } \\
\text { number }\end{array}$ & $\begin{array}{c}\text { Internodes } \\
\text { number }\end{array}$ & $\begin{array}{c}\text { Panicle } \\
\text { length }\end{array}$ & $\begin{array}{c}\text { Total grain/ } \\
\text { panicle }\end{array}$ & $\begin{array}{c}\text { 100-grain } \\
\text { weight }(\mathbf{g})\end{array}$ \\
\hline IPB WT & $141.6 \mathrm{a}$ & $121.4 \mathrm{a}$ & $5.4 \mathrm{ab}$ & $5.0 \mathrm{a}$ & $27.9 \mathrm{~b}$ & $152.9 \mathrm{~b}$ & $2.9 \mathrm{a}$ \\
IPB T- & $131.8 \mathrm{a}$ & $114.3 \mathrm{a}$ & $7.2 \mathrm{a}$ & $5.0 \mathrm{a}$ & $31.0 \mathrm{a}$ & $212.8 \mathrm{a}$ & $2.8 \mathrm{~b}$ \\
IPB 8-3 & $99.5 \mathrm{~b}$ & $87.0 \mathrm{~b}$ & $2.0 \mathrm{~b}$ & $5.0 \mathrm{a}$ & $20.5 \mathrm{~b}$ & $54.0 \mathrm{c}$ & $2.5 \mathrm{~b}$ \\
IPB 8-4 & $113.5 \mathrm{~b}$ & $98.5 \mathrm{~b}$ & $2.0 \mathrm{~b}$ & $4.5 \mathrm{~b}$ & $27.8 \mathrm{~b}$ & $92.5 \mathrm{c}$ & $2.9 \mathrm{a}$ \\
IPB 8-6 & $117.0 \mathrm{c}$ & $90.5 \mathrm{~b}$ & $2.0 \mathrm{~b}$ & $5.0 \mathrm{a}$ & $27.5 \mathrm{~b}$ & $84.0 \mathrm{c}$ & $3.1 \mathrm{a}$ \\
IPB 14-10 & $104.6 \mathrm{c}$ & $88.6 \mathrm{~b}$ & $4.0 \mathrm{a}$ & $4.0 \mathrm{~b}$ & $28.3 \mathrm{~b}$ & $134.6 \mathrm{~b}$ & $3.2 \mathrm{a}$ \\
IPB 14-12 & $109.1 \mathrm{c}$ & $104.6 \mathrm{~b}$ & $4.0 \mathrm{a}$ & $5.0 \mathrm{a}$ & $40.3 \mathrm{a}$ & $165.3 \mathrm{~b}$ & $2.9 \mathrm{a}$ \\
\hline
\end{tabular}

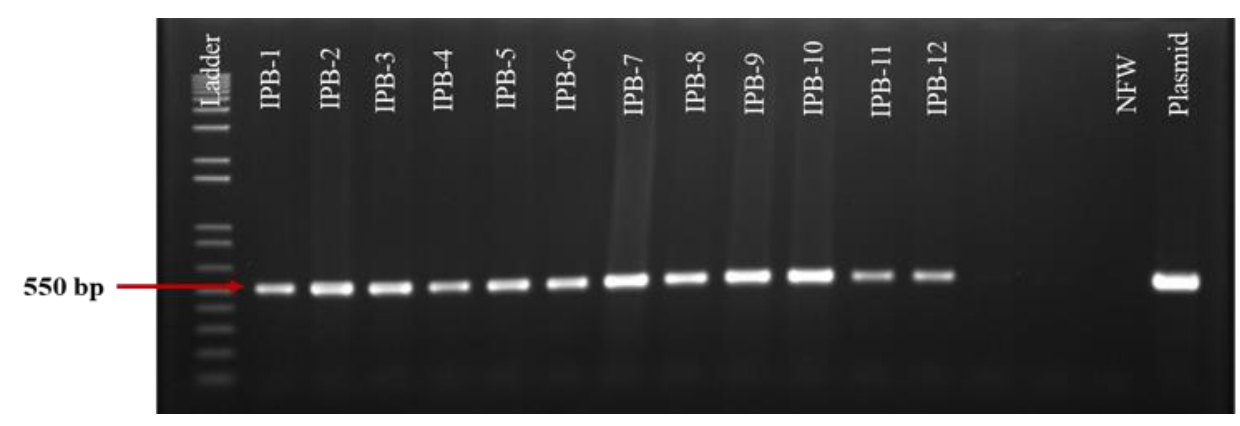

Figure 3. Gel photograph of PCR amplified product using hpt specific primers, DNA templates isolated from T0 lines. Bands of DNA fragments in the IPB-2 - IPB-13 indicated the samples were positively carrying the hpt transgene. The expected amplicon size for the hpt gene was approximately $550 \mathrm{bp}$. NFW: PCR reaction using nuclease-free water as the template, used as no template control. Plasmid: PCR reaction using plasmid as templates, used as the positive control

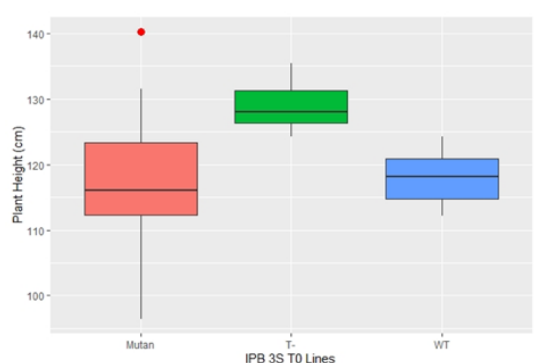

(A)

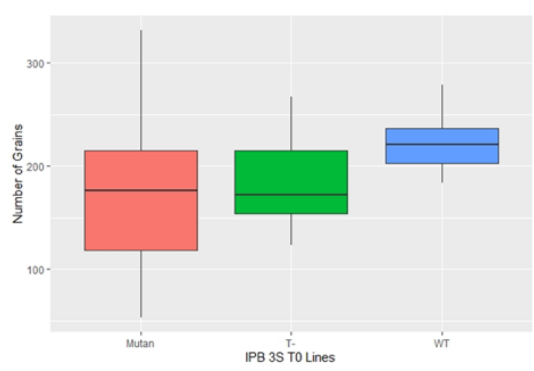

(D)

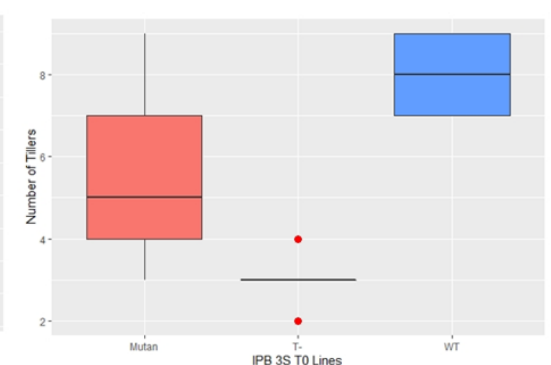

(B)

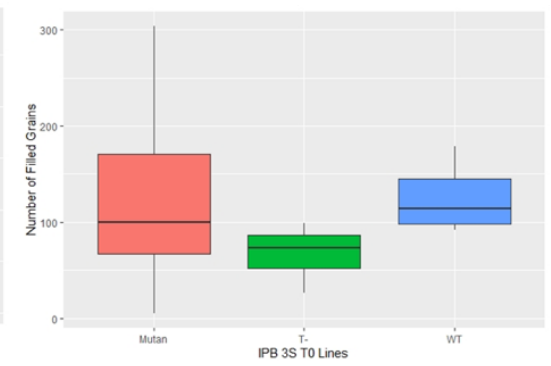

(E)

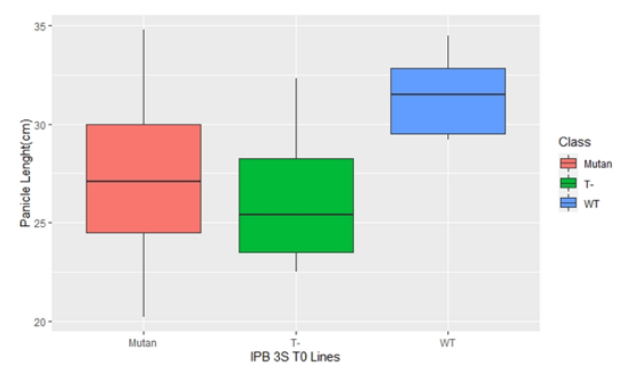

(C)

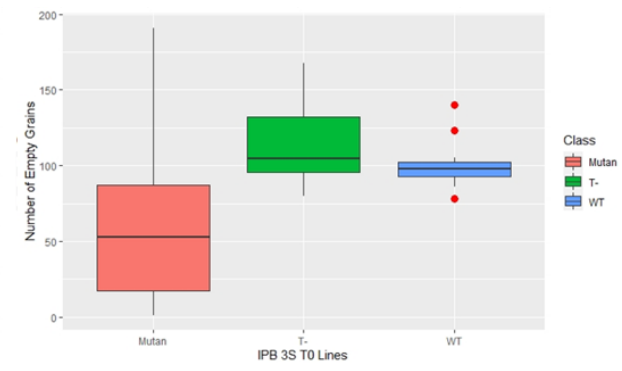

(F)

Figure 4. The distribution of the observed characters in the regenerated T0 plants: A. Plant height, B. Tiller numbers/plant, C. Panicle length, D. Total grains/panicle, E. Filled grains/panicle, F. Empty grain/panicle 


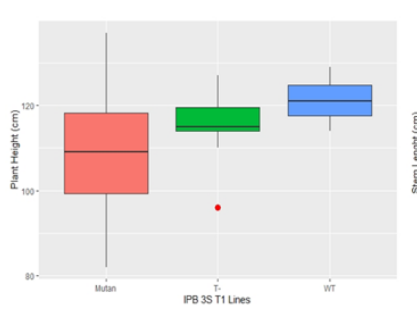

(A)

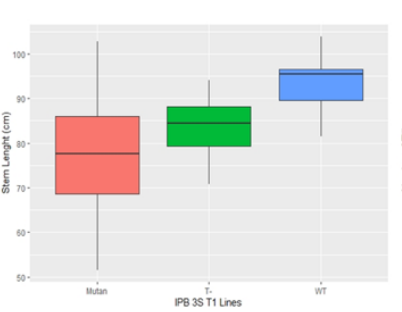

(B)

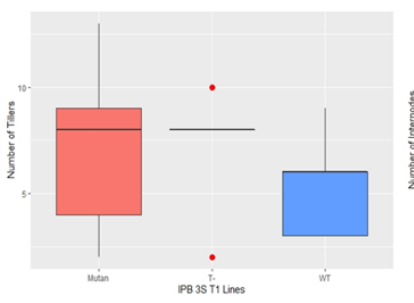

(C)

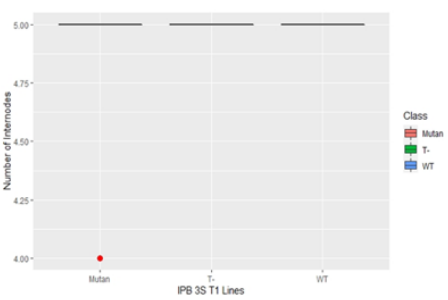

(D)

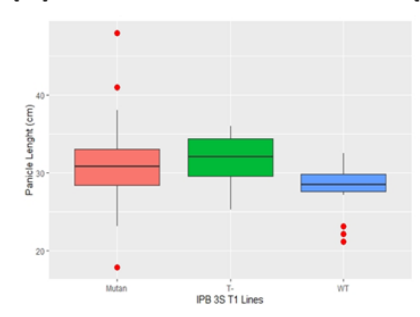

(E)

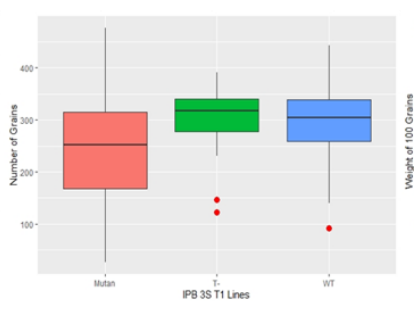

(F)

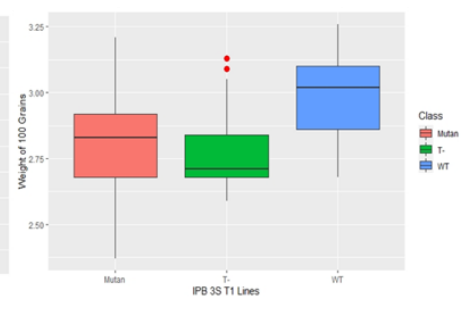

(G)

Figure 5. The distribution of the observed character in T1 involved (A) plant height, (B) stem length, (C) tiller number, (D) internodes number, (E) panicle length, $(\mathrm{F})$ total grain number per panicle, (G) 100-grain weight

Interestingly, IPB-14-12 has a panicle length of 40.3 $\mathrm{cm}$, which was significantly longer than the wildtype and negative transformants. This was followed by total grains of 165.3 per panicle that makes this individual has very potential to be analyzed in the next generation. In addition, IPB-14-10 also showed a potential that is not much different. It has a panicle length of $28.3 \mathrm{~cm}$ followed by 134.6 total grains and 3.2 grams of 100 -grains weight. The distribution of the observed character is shown in Figure 5.

The changes in plant height and stem length caused by the Cas9 enzyme endonuclease, transformed into the plant genome, have worked to edit the target gene. Mutations that occur in the $G A_{20} O x 2$ gene cause the biosynthesis of GA in plants to be inhibited. The concentration of GA in mutant lines was lower than the wildtype, and then the plant posture becomes shorter than the wildtype (Spielmeyer et al. 2002; Dello-Ioio et al. 2007).

\section{Confirmation of T1 lines mutagenesis using DNA sequencing analysis}

There were five T1 plants (IPB-8-3, IPB-8-4, IPB-8-6, IPB-14-10, and IPB-14-12) in the evaluated population showing changes in plant height and stem length characters. Subsequently, DNA samples of the T1 lines were used as a template for PCR amplification using primers flanking the target gRNAs. The PCR products were sequenced and the sequencing results were analyzed using the Geneious software version 10.0.3. The generated PCR amplified product was approximately $1300 \mathrm{bp}$.

Only IPB8-4 and IPB-14-10 generated PCR amplified products using the evaluated GA20 primers while IPB-8-3,
IPB-8-6, and IPB-14-12 did not. This indicated that probably mutations are occurring in regions of primer annealing sites in the DNA templates. Therefore, new primers to amplify longer DNA fragments were designed for those three mutant lines. PCR amplification using new primer sets was able to generate PCR products. However, sequencing analyses for the new PCR products were not conducted.

In Table 7, sequences highlighted in blue indicated the sgRNA-1 sequences while those in purple indicated the sgRNA-2. The nucleotide highlighted in red indicated substitution, in yellow indicated insertion, and in green indicated deletion mutations. Table 7 also showed that IPB8-4 has three insertions, four deletions, and fifteen substitutions mutations, while IPB-14-10 has nine insertions, nine deletions, and forty-three substitution mutations compared to the wildtype sequences.

In this study, the nucleotide mutations in the target sequences were obtained after introducing the CRISPR/Cas9 $G_{20} O \times 2$ cassettes. Furthermore, the amino acid residues also changed because of the nucleotide changes. The GA20 oxidase is needed in the final stages of the Gibberellin biosynthetic pathway (Spielmeyer et al. 2002). The SD1 genes encode GA20 oxidase and GA20 oxidase catalyzes three steps in the GA53-GA44-GA19GA20 biosynthetic pathway. Analysis showed that the GA20 accumulation was lower in the $s d l$ mutant than that in the wildtype SDI genes (Ashikari et al. 2002). Many agronomical traits are related to rice yields, such as tiller numbers and panicle numbers per plant, grain numbers per panicle, and 1000-grain weight (Zeng et al. 2020). 
Table 7. Nucleotide sequences T1 lines on target sequence using GA20 forward and reverse primers

\begin{tabular}{|c|c|c|}
\hline Genotypes & Nucleotide sequences between the two gRNA target & $\begin{array}{c}\text { Type and number } \\
\text { of mutation* }\end{array}$ \\
\hline IPB-WT & TTGGAAATGCTCTCCACCCACCTTACTATAATT-GATTCCAGGAAATTCCAATTACTATCT & Wildtype sequence \\
\hline IPB-8-4 & TTGGAAATGCTCTCCACCCCCCTTCCTATAATÄGGATTCCAGGAAATTC--AATACTATCC & $3 \mathrm{i} / 4 \mathrm{~d} / 15 \mathrm{~s}$ \\
\hline IPB-14-10 & TÄGGAATGCTCTCCAACCACCTTCCAАT & $9 \mathrm{i} / 9 \mathrm{~d} / 43 \mathrm{~s}$ \\
\hline IPB-WT & ACGAG-ATGTG-CAGCTGTATCATTCTGGTACTGA-----CAGATAAGCTTCTTTATCTCC & \\
\hline IPB-8-4 & ATGAG-ATGTGC-AGCTGTATCATTCGGGTCCTGT----TCAGATAAGCTTCTTTATTCC- & \\
\hline IPB-14-10 & & \\
\hline IPB-WT & -TTCACGCTCATCACTTTCACA-ACCACATGGCTTGGGTCCTCTATGATAGTT & \\
\hline IPB-8-4 & -TTCACGCTCATCACTTCCACA-ACCACATGGCTCGGGTCCTCTCTCATAGTC & \\
\hline IPB-14-10 & AAAAAGGCTTAGCAAATGCACAT-CCTCACCGCTCGGCTCCTCCCTCATTGCC & \\
\hline
\end{tabular}

Note: i: insertion, d: deletion, and s: substitution mutations

In this study, we successfully regenerated IPB3S T0 transgenic lines carrying CRISPR/Cas9 $\mathrm{GA}_{20} O \times 2$ construct by using Agrobacterium-mediated genetic transformation and plantlet regeneration in a modified regeneration medium. As many as 24 IPB3S T0 lines positively carrying the $h p t$ gene were identified. Transformation efficiency was $19.3 \%$. The best medium for regenerating IPB3S plantlets was the A medium with a regeneration efficiency of $73.3 \%$. Two possible T0 mutants derived from genome editing having shorter plant height than the wild types were identified (IPB-8 and IPB-14). Five T1 progenies (IPB-8-3, IPB-8-4, IPB-8-6, IPB-14-10, and IPB-14-12) derived from both genome-edited T0 mutants (IPB-8 and IPB-14) also showed shorter height compared to the wildtype and the non-transformed regenerants. The DNA sequencing analysis indicated the presence of various substitution, insertion, and deletion mutations for the editing target sites in IPB-8-4 and IPB-14-10. Such data confirmed the effectiveness of CRISPR/Cas9 genome editing of rice cV IPB3S to obtain mutants having shorter heights.

\section{ACKNOWLEDGEMENTS}

The author thanks Molecular Biology Laboratory and the Indonesian Agency for Agricultural Research and Development, the Indonesian Ministry of Agriculture for giving the research support, facilities, and funding the Research. Part of this research was supported by the Indonesian Agency for Agricultural Research and Development (IAARD), Project No. 1798.101.002.053, entitle "Application of CRISPR/Cas9 genome editing technique for improving lodging resistance and productivity in rice" coordinated by Tri Joko Santoso.

\section{REFERENCES}

Ashikari M, Sasaki A, Ueguchi-Tanaka M, Itoh H, Nishimura A, Datta S, Ishiyama K, Saito T, Kobayashi M, Khush GS. 2002. Loss-offunction of a rice gibberellin biosynthetic gene, GA20 oxidase (GA20ox-2), led to the rice "green revolution." Breed Sci 52 (2): 143 150. DOI: $10.1270 /$ jsbbs.52.143.
Chen S, Wang X, Zhang L, Lin S, Liu D, Wang Q, Cai S, El-Tanbouly R, Gan L, Wu H. 2016. Identification and characterization of tomato gibberellin 2-oxidases (GA2oxs) and effects of fruit-specific S1GA2ox1 overexpression on fruit and seed growth and development. Hortic Res 3: 16059. DOI: 10.1038/hortres.2016.59.

Chhun T, Aya K, Asano K, Yamamoto E, Morinaka Y, Watanabe M, Kitano H, Ashikari M, Matsuoka M, Ueguchi-Tanaka M. 2007. Gibberellin regulates pollen viability and pollen tube growth in rice. Plant Cell 19 (12): 3876-3888. DOI: 10.1105/tpc.107.054759.

Cong L, Ran FA, Cox D, Lin S, Barreto R, Habib N, Hsu PD, Wu X, Jiang W, Marraffini LA. 2013. Multiplex genome engineering using CRISPR/Cas Systems. Science 339: 819-824. DOI: 10.1126/science.1231143.

Davière JM, Achard P. 2013. Gibberellin signaling in plants. $\begin{array}{llll}\text { Development (Cambridge) } 140 & \text { (6): } 1147-1151 . & \end{array}$ 10.1242/dev.087650.

Davies PJ. 2004. Plant Hormones: Biosynthesis, Signal Transduction, Action. Kluwer Academic Publishers, Dordrecht. DOI: 10.1017/CBO9781107415324.004.

Dello-Ioio R, Linhares FS, Scacchi E, Casamitjana-Martinez E, Heidstra R, Costantino P, Sabatini S. 2007. Cytokinins determine Arabidopsis root-meristem size by controlling cell differentiation. Curr Biol 17 (8): 678-682. DOI: 10.1016/j.cub.2007.02.047.

Ge X, Chu Z, Lin Y, Wang S. 2006. A tissue culture system for different germplasms of indica rice. Plant Cell Rep 25 (5): 392-402. DOI: 10.1007/s00299-005-0100-7.

Han Y, Teng K, Nawaz G, Feng X, Usman B, Wang X, Luo L, Zhao N, Liu Y, Li R. 2019. Generation of semi-dwarf rice (Oryza sativa L.) lines by CRISPR. Biotech 9: 387. DOI: 10.1007/s1320 5-019-1919-x.

Hiei Y, Komari T. 2006. Improved protocols for transformation of indica rice mediated by Agrobacterium tumefaciens. Plant Cell, Tissue and Organ Culture 85 (3): 271-283. DOI: 10.1007/s11240-005-9069-8.

Hiei Y, Komari T. 2008. Agrobacterium-mediated transformation of rice using immature embryos or calli induced from mature seed. Nat Protocols 3 (5): 824-834. DOI: 10.1038/nprot.2008.46.

Itoh H, Ueguchi-Tanaka M, Sakamoto T, Kayano T, Tanaka H, Ashikari M, Matsuoka M. 2002. Modification of rice plant height by suppressing the height-controlling gene D18 in rice. Breed Sci 52 (3): 215-218. DOI: $10.1270 /$ jsbbs.52.215.

Jiang W, Zhou H, Bi H, Fromm M, Yang B, Weeks DP. 2013. Demonstration of CRISPR/Cas9/sgRNA-mediated targeted gene modification in Arabidopsis, tobacco, sorghum and rice. Nucleic Acids Res 41 (20): e188. DOI: 10.1093/nar/gkt780.

Jinek M, Chylinski K, Fonfara I, Hauer M, Doudna JA, Charpentier E. 2012. A programmable dual-RNA-guided DNA endonuclease in adaptive bacterial immunity. Science 337: 816-821. DOI: $10.1126 /$ science. 1225829 .

Khush GS. 2005. What it will take to Feed 5.0 billion rice consumers in 2030. Plant Mol Biol 59 (1): 1-6. DOI: 10.1007/s11103-005-2159-5.

Lin YJ, Zhang Q. 2005. Optimising the tissue culture conditions for high efficiency transformation of indica rice. Plant Cell Rep 23 (8): 540547. DOI: $10.1007 / \mathrm{s} 00299-004-0843-6$. 
Liu C, Zheng S, Gui J, Fu C, Yu H, Song D, Shen J, Qin P, Liu X, Han B. 2018. Shortened basal internodes encodes a gibberellin 2 -oxidase and contributes to lodging resistance in rice. Mol Plant 11 (2): 288-299. DOI: 10.1016/j.molp.2017.12.004.

Miki B, McHugh S. 2004. Selectable marker genes in transgenic plants: Applications, alternatives and biosafety. J Biotechnol 107 (3): 193232.DOI: 10.1016/j.jbiotec.2003.10.011.

Ogawa Y, Mii M. 2007. Meropenem and moxalactam: Novel $\beta$-lactam antibiotics for efficient Agrobacterium-mediated transformation. Plant Sci 172 (3): 564-572. DOI: 10.1016/j.plantsci.2006.11.003.

Ramesh M, Murugiah V, Gupta AK. 2009. Efficient in vitro plant regeneration via leaf base segments of indica rice (Oryza sativa L.) Indian J Exp Biol 47 (1): 68-74.

Sahoo RK, Tuteja N. 2012. Development of Agrobacterium-mediated transformation technology for mature seed-derived callus tissues of indica rice cultivar IR64. GM Crops and Food 3 (2): 123-128. DOI: 10.4161/gmcr.20032.

Sasaki A, Ashikari M, Ueguchi-Tanaka M, Itoh H, Nishimura A, Swapan D, Ishiyama K, Saito T, Kobayashi M, Khush GS. 2002. A mutant gibberellin-synthesis gene in rice: New insight into the rice variant that helped to avert famine over thirty years ago. Nature 416: 701702. DOI: $10.1038 / 416701 \mathrm{a}$.

Slamet-Loedin IH, Chadha-Mohanty P, Torrizo L. 2014. AgrobacteriumMediated Transformation: Rice Transformation Methods. Humana Press Springer, London. DOI: 10.1007/978-1-62703-715-0.

Spielmeyer W, Ellis MH, Chandler PM. 2002. Semidwarf (sd-1), "green revolution" rice, contains a defective gibberellin 20-oxidase gene.
Proceedings of the National Academy of Sciences of the United States of America 99 (13): 9043-9048. DOI: 10.1073/pnas.132266399

Thomas SG, Hedden P. 2018. Gibberellin metabolism and signal transduction. Ann Plant Rev 24 (15): 147-184. DOI: 10.1002/9781119312994.apr0247.

Vennapusa AR, Vemanna RS, Reddy BH, Babitha KC, Kiranmai K, Nareshkumar A, Sudhakar C. 2015. An efficient callus induction and regeneration protocol for a drought tolerant rice indica genotype AC39020. J Plant Sci 3 (5): 248. DOI: 10.11648/j.jps.20150305.11

Wang E, Wang J, Zhu X, Hao W, Wang L, Li Q, Zhang L, He W, Lu B, Lin H. 2008. Control of rice grain-filling and yield by a gene with a potential signature of domestication. Nat Genet 40 (11): 1370-1374. DOI: $10.1038 / \mathrm{ng} .22$.

Wang Y, Li J. 2011. Branching in rice. Current Opinion in Plant Biology 14 (1): 94-99. DOI: 10.1016/j.pbi.2010.11.002.

Wiedenheft B, Sternberg SH, Doudna JA. 2012. RNA-guided genetic silencing systems in bacteria and archaea. Nature 482 (7385): 331338. DOI: $10.1038 /$ nature 10886 .

Xing Y, Zhang Q. 2010. Genetic and molecular bases of rice yield. Ann Rev Plant Biol 61: 421-442. DOI: 10.1146/annurev-arplant-042809112209.

Zeng Y, Wen J, Zhao W, Wang Q, Huang W. 2020. Rational improvement of rice yield and cold tolerance by editing the three genes OsPIN5b, GS3, and OsMYB30 with the CRISPR-Cas9 system. Front Plant Sci 10: 1663. DOI: 10.3389/fpls.2019.01663. 